\title{
Perancangan dan Pembuatan Alat Pendeteksi Tingkat Kebisingan Bunyi Berbasis Mikrokontroler
}

\author{
Suyatno* dan Ahmad Hisam \\ Jurusan Fisika-FMIPA, Institut Teknologi Sepuluh Nopember \\ Kampus ITS Sukolilo, Surabaya 61111
}

\begin{abstract}
Intisari
Telah dibuat alat pendeteksi tingkat kebisingan bunyi sebagai sistem peringatan terhadap bahaya kebisingan dan menggunakan mikrokontroler sebagai media pengolah data. Alat yang dibuat memiliki kemampuan pengukuran \pm 58 sampai dengan $\pm 95 \mathrm{dBA}$, dan mampu memberikan informasi kebisingan dalam tiga keadaan, yaitu aman, ambang batas bahaya, dan sangat bahaya yang di indikasikan dengan nyala lampu peringatan.
\end{abstract}

KATA KUNCI: mikrokontroler, SPL, kebisingan, early warning

\section{PENDAHULUAN}

Di dalam aktifitas sehari-hari, terutama aktifitas bekerja, banyak hal yang sering dibicarakan mengenai kenyamanan dalam bekerja, salah satunya adalah terganggunya kenyamanan tersebut yang disebabkan oleh bunyi bising yang diterima. Dikarenakan keberadaan kebisingan ini sangat mengganggu aktifitas dalam bekerja, maka masalah kebisingan ini mendapatkan perhatian yang serius dikalangan para pekerja, terutama pekerja di industri-industri yang menggunakan mesin-mesin berat. Oleh karena itu perlu adanya alat yang dapat mengukur tingkat tekanan bunyi, sehingga masalah kebisingan dapat segera ditangani. Selain itu kebisingan juga berpengaruh terhadap keamanan dan keselamatan kerja (K3) yang tentunya akan sangat menentukan hasil dan kualitas kerja pada suatu produksi.

Perancangan dan pembuatan alat ini bertujuan untuk mengetahui tingkat kebisingan bunyi, dan dapat memberikan informasi tentang level kebisingan dalam tiga keadaan, yaitu aman, batas bahaya, dan sangat bahaya.

\section{TINJAUAN PUSTAKA}

\section{Bunyi}

Bunyi adalah perubahan tekanan yang dapat dideteksi oleh telinga manusia yang merambat melalui suatu medium, karena adanya perubahan tekanan yang berulangulang. Manusia mendengar bunyi saat gelombang bunyi merambat melalui udara atau medium lain, sampai kegendang telinga manusia. Batas frekuensi bunyi yang dapat didengar oleh telinga manusia kira-kira dari $20 \mathrm{~Hz}$ sampai $20 \mathrm{kHz}$ dan batas ini disebut Audiosonik, sedangkan diatas $20 \mathrm{kHz}$ disebut ultrasonic dan dibawah $20 \mathrm{~Hz}$ disebut infrasonik.

\footnotetext{
*E-MAIL: kangyatno@physics.its.ac.id
}

Besaran bunyi yang sering berhubungan erat dengan pendengaran manusia adalah tingkat tekanan bunyi atau Sound Pressure Level (SPL). Besaran ini adalah logaritma dari rasio tekanan terhadap suatu tekanan acuan dan secara matematis dinyatakan dengan persamaan berikut :

$$
S P L=10 \log \left(P^{2} / P_{a c}^{2}\right) d B
$$

dengan, $\mathrm{P}$ adalah tekanan bunyi yang akan dinyatakan dalam $\mathrm{dB}, \mathrm{P}_{a c}$ adalah tekanan bunyi acuan yang besarnya $2.10^{-5} \mathrm{~Pa}$.

Kebisingan adalah bunyi yang tidak dikehendaki dan dapat mengganggu kesehatan dan kenyamanan lingkungan. Efek bising terhadap pendengaran dapat dibagi menjadi tiga kelompok, yaitu trauma akustik, perubahan ambang pendengaran akibat bising yang berlangsung sementara (noise induced temporary threshold shift) dan perubahan ambang pendengaran akibat bising yang berlangsung permanen (noise-induced permanent threshold shift).

Keputusan Menteri Kesehatan RI 718/MEN.KES /PER/XI/1987, mengenai batas maksium kebisingan untuk berbagai jenis daerah ditunjukkan pada Tabel 1 .

Secara umum, sistem pengukuran fisis sebuah piranti alat ukur terdiri dari bagian-bagian seperti ditunjukkan Gambar 1.

TABEL I: Peraturan MENKES RI Mengenai Batas maksimum Kebisingan untuk berbagai daerah.

\begin{tabular}{|c|c|c|c|}
\hline Zona & $\begin{array}{l}\text { Jenis } \\
\text { daerah }\end{array}$ & $\begin{array}{l}\text { Batas Maks } \\
\text { Dianjurkan }\end{array}$ & $\begin{array}{l}\text { imum(dBA) } \\
\text { Dibolehkan }\end{array}$ \\
\hline A & Rumah Sakit & 35 & 45 \\
\hline B & $\begin{array}{l}\text { Perumahan, } \\
\text { Sekolah, } \\
\text { Rekreasi }\end{array}$ & 45 & 55 \\
\hline C & $\begin{array}{l}\text { Perkantoran, } \\
\text { Pertokoan, } \\
\text { Pasar }\end{array}$ & 50 & 60 \\
\hline D & $\begin{array}{l}\text { Industri, } \\
\text { Pabrik, } \\
\text { Stasiun Kereta Api, } \\
\text { Terminal }\end{array}$ & 60 & 70 \\
\hline
\end{tabular}




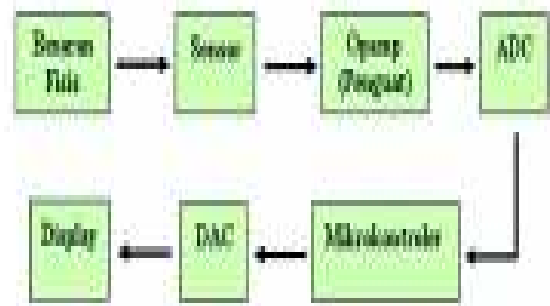

Gambar 1: Diagram Blok Alat Ukur Secara Umum

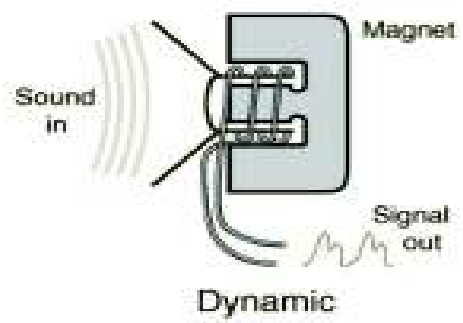

Gambar 2: Mikropon Dinamik

\section{Mikrofon Sebagai Sensor Bunyi.}

Mikrofon merupakan peralatan yang dibuat untuk menangkap gelombang di udara dan mengubahnya menjadi sinyal listrik. Desain yang paling umum menggunakan membran tipis yang getarannya dapat merespon tekanan bunyi. Salah satu jenisnya adalah moving coil microphone (mikrofon dinamik), Dynamic microphones bekerja melalui induksi elektromagnetik. Prinsip dinamisnya sama dengan loudspeaker, hanya kebalikannya, yaitu kumparan induksi yang mudah bergerak yang diletakkan pada medan magnet dari magnet permanen, dilekatkan pada difragma. Ketika bunyi masuk windscreen, gelombang bunyi menggerakkan diafragma. Ketika difragma bergetar, kumparan bergerak dalam medan magnet, menghasilkan arus dalam kumparan.

\section{Penguat Operasional.}

Penguat Operasional (Op-amp) adalah suatu blok penguat yang mempunyai dua masukan dan satu keluaran. Op-amp biasa terdapat di pasaran berupa rangkaian terpadu integrated circuit (IC).

Gambar 3 menunjukkan sebuah blok Opamp yang mempunyai berbagai tipe dalam bentuk IC. Seperti terlihat pada Gambar 4, opamp memiliki masukan tak membalik v+ (noninverting), masukan membalik v- (inverting) dan keluaran vo.

\section{ADC (Analog to Digital Converter).}

ADC adalah sebuah piranti yang dirancang untuk mengubah sinyal-sinyal analog menjadi bentuk sinyal digital. IC

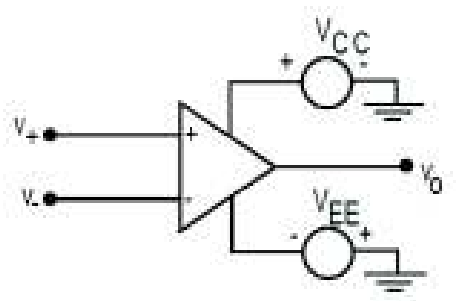

Gambar 3: Rangkaian dasar penguat operasiaonal

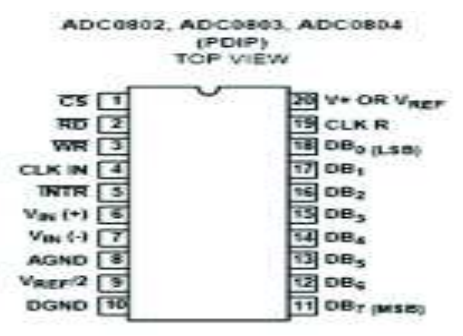

Gambar 4: Pin konfigurasi ADC 0804

ADC 0804 dianggap dapat memenuhi kebutuhan dari rangkaian yang akan dibuat. IC jenis ini bekerja secara cermat dengan menambahkan sedikit komponen sesuai dengan spesifikasi yang harus diberikan dan dapat mengkonversikan secara cepat suatu masukan tegangan.

\section{Rangkaian Digital.}

\section{A. Mikrokontroler AVR.}

Mikrokontroller AVR memiliki arsitektur RISC 8 Bit, sehingga semua instruksi dikemas dalam kode 16-bit (16-bits word) dan sebagian besar instruksi dieksekusi dalam satu siklus instruksi clock. Hal ini sangat membedakan sekali dengan instruksi MCS-51 (Ber-arsitektur CISC) yang membutuhkan siklus 12 clock.

AVR dikelompokkan kedalam 4 kelas, yaitu ATtiny, keluarga AT90Sxx, keluarga ATMega, dan keluarga AT86RFxx. Dari kesemua kelas yang membedakan satu sama lain adalah ukuran onboard memori, on-board peripheral dan fungsinya. Dari segi arsitektur keduanya bisa dikatakan hampir sama.

\section{B. Unit Tampilan (Display)}

Unit tampilan keluaran suatu alat ukur merupakan indikator yang menyatakan hasil pengukuran suatu masukan, dan biasanya dapat berupa pergerakan sebuah jarum, nyala lampu, bunyi alarm, nilai angka pada seven segment, tulisan atau angka pada LCD, dan masih banyak lagi jenis dan ragamnya. Pemilihan jenis display ini disesuaikan dengan jenis besaran suatu obyek yang akan diukur, sehingga seseorang yang melakukan pengukuran dapat dengan mudah mengetahui dan memahami informasi yang dihasilkan oleh alat ukur, dan hasilnya adalah kondisi obyek yang diukur dapat diketahui kedaannya dengan jelas. 


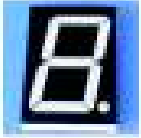

Sewn Segued

LCDuknat6 $\times 2$

Gambar 5: Beberapa contoh jenis Display

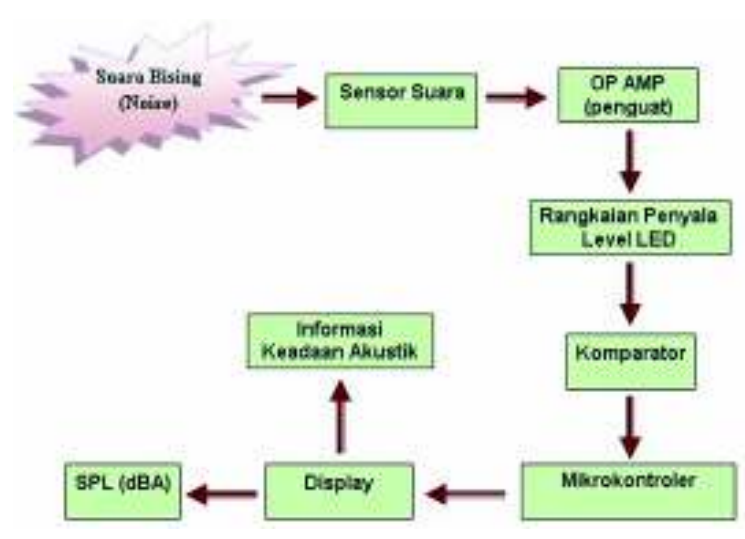

Gambar 6: Diagram alir alat pendeteksi kebisingan bunyi

\section{METODOLOGI}

Perancangan dan pembuatan alat pengukur tingkat kebisingan bunyi ini terdiri dari beberapa blok bagian, seperti ditunjukkan Gambar 6.

Alur dan cara kerja dari alat secara keseluruhan adalah ketika sensor menangkap bunyi dengan level tertentu, maka sensor manghasilkan arus listrik dari proses ggl induksi yang terjadi di dalamnya. Besarnya arus listrik ini masih sangat lemah sehingga memerlukan rangkaian penguat supaya data dapat diolah. Rangkaian penguat yang digunakan adalah menggunakan Amplifier jenis BTL. Selanjutnya data yang sudah dikuatkan tersebut di proses oleh rangkaian penyala Level LED untuk menyalakan sepuluh LED secara berurutan tergantung pada besarnya sinyal masukan yang diterima. LED yang menyala tersebut merupakan data yang dikirimkan menuju rangkaian selajutnya, dan dikarenakan data yang di hasilkan ini masih dalam bentuk data Analog, maka masih memerlukan proses lebih lanjut supaya menjadi data digital. Proses pengubahan data tersebut menggunakan rangkaian komparator, sehingga data dapat dengan mudah diolah oleh mikrokontroler. Data hasil pengolahan oleh mikrokontroler ini selanjutnya ditampilkan oleh unit keluaran (Dislay) berupa angkaangka pada Seven Segment yang menyatakan besarnya tingkat tekanan bunyi (SPL) yang terukur.

\section{HASIL DAN PEMBAHASAN}

Pengambilan data yang dilakukan menggunakan sampel bunyi yang dikeluarkan oleh komputer dengan menggunakan software TrueRTA, dan dari pengujian alat yang telah di- lakukan, didapatkan data yang menyatakan hasil pengukuran oleh alat buatan jika dibandingkan dengan SLM NL-20. Datadata tersebut adalah sebagai berikut:

1. Korelasi data SPL oleh SLM dengan tegangan sensor pada alat.

Pada waktu Pengujian alat, sumber bunyi di aktifkan dari level yang rendah sampai dengan level yang tinggi. Bunyi ditahan pada level-level bunyi yang berbeda yang ditandai dengan menyalanya sepuluh LED secara berurutan. Pada tiap - tiap menyalanya LED ini, nilai SPL yang terbaca oleh SLM dicatat, dan pada waktu yang bersamaan dicatat pula besarnya tegangan yang dihasilkan oleh rangkaian sensor, sehingga dari pengujian tersebut dapat diketahui besarnya tegangan sensor pada saat SPL tersebut diterima oleh alat.

2. Hubungan antara SPL yang terukur pada SLM NL-20 dengan SPL Pada Alat.

Dari pengujian alat yang telah dilakukan, sumber bunyi diaktifkan dan volumenya di hentikan / di tahan pada nilai tertentu, kemudian dicatat nilai SPL yang terukur oleh SLM dengan SPL yang terukur oleh alat buatan, dan pengambilan data dilakukan dengan 12 tingkat volume yang berbeda. Berikut disajikan tabel nilai SPL dari hasil pengujian alat terhadap SPL yang terbaca pada SLM NL-20.

Dari Tabel II, dapat dibuat grafik perbandingan antara keduanya, seperti pada Gambar 7, dan didapatkan persamaan $\mathrm{y}=0.9762 \mathrm{x}+2.8409$, dengan y adalah pembacaan SPL oleh SLM (dBA), x menyatakan pembacaan SPL oleh alat buatan (dBA). Dari persamaan tersebut, dapat diketahui bahwa keseksamaan antara SLM NL-20 dengan SLM alat buatan adalah sebesar 0.9888 , atau sebesar $98.88 \%$.

\section{SIMPULAN}

1. Kemampuan deteksi SPL yang dapat terukur oleh alat buatan adalah antara $\pm 58 \mathrm{dBA}$ sampai $\pm 95 \mathrm{dBA}$.

TABEL II: Hubungan antara SPL pada alat terhadap SPL pada SLM NL-20

\begin{tabular}{lcc}
\hline \hline No & SPL pada & SPL pada \\
& alat(DBA) & SLM NL-20 (dBA) \\
1 & 58 & 59.6 \\
2 & 62 & 64.6 \\
3 & 67 & 67.6 \\
4 & 70 & 69.2 \\
5 & 73 & 74.0 \\
6 & 78 & 79.4 \\
7 & 83 & 85.5 \\
8 & 88 & 89.4 \\
9 & 92 & 90.3 \\
10 & 95 & 96.6 \\
\hline \hline
\end{tabular}




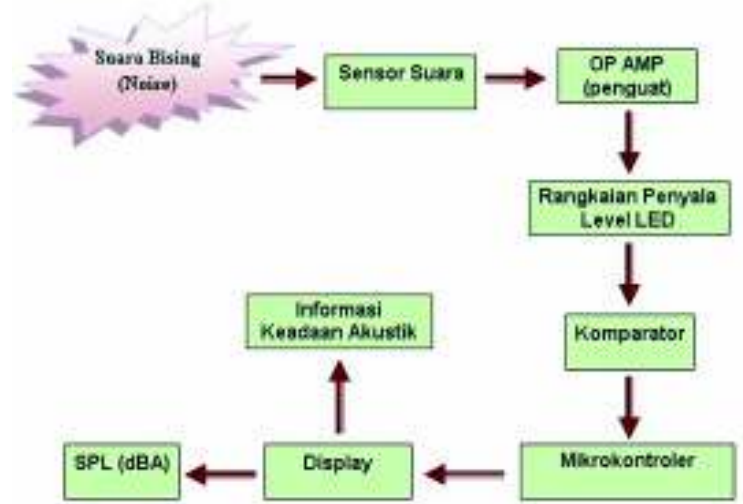

Gambar 7: Grafik hubungan antara SPL oleh SLM terhadap SPL oleh alat buatan
2. Alat yang dibuat hanya dapat mengukur tingkat kebisingan berdasarkan nilai SPL-nya, bukan berdasarkan pada Frekuensinya.

3. alat yang dibuat dapat digunakan sebagai alat untuk mendeteksi tingkat kebisingan di suatu lokasi, dan akan memberikan informasi kepada orang disekitar tentang kondisi yanga ada. Akibatnya dapat dilakukan tindakan tertentu terhadap kondisi yang terjadi
[1] Eko putro, Agfianto, Belajar Mikrokontroler (Penerbit Gava Media, Yogyakarta, 2003).

[2] Prasetio, Lea, Akustik (Jurusan Fisika FMIPA Institut Teknologi Sepuluh Nopember, Surabaya, 2003)

[3] Malvino, Prinsip-Prinsip Elektronika (Erlangga, Jakarta, 1995).

[4] Millman, Halkias., Elektronika Terpadu (Erlangga, Jakarta, 1997).

[5] http://www.kemt.fei.tuke.sk/Predmety/KEMT320EA/web/Online
Course on Acoustics/index-3.html

[6] http://www.google.co.id/search?hl=id /q=Dampak Kebisingan Terhadap Kesehatan btnG=Telusuri meta.html

[7] http://putraprabu.wordpress.com/2008/12/30/ jenis dan penyebab kebisingan.html

[8] http://putraprabu.wordpress.com/2009/01/02/ pengukuran nilaiambang-dan-zona-kebisingan/.html 